\title{
Pricing Challenges in Export Contracts of Gas Industry of Iran; Capacities and Obstacles
}

\author{
Fakhredin Aboieyeh ${ }^{1} \&$ Aye Katebi ${ }^{1}$ \\ ${ }^{1}$ Law Faculty, Islamic Azad University, Damghan Branch, Damghan, Iran \\ Correspondence: Fakhredin Aboieyeh, Law faculty, Islamic Azad University, Damghan Branch, Damghan, Iran. \\ E-mail: falboye@yahoo.com
}

Received: April 28, 2016 Accepted: May 25, 2016 Online Published: June 29, 2016

doi:10.5539/jpl.v9n5p117 URL: http://dx.doi.org/10.5539/jpl.v9n5p117

\begin{abstract}
The present study is conducted via library and field method and implementing interviews. First, general issues in terms of natural gas and its market and its features within Persian Gulf and the past and present of the gas industry of the country has been explored to facilitate entering the main discussion and found out that the gas market is a local market and lack of recognizing a basic price in Persian Gulf and in particular in Iran caused that despite its superior position among resources not to have an efficient impact so far and in continuation gas export contract conditions and common formula analysis were analyzed to find out how apposite pricing formula can be arranged. The obtained results showed that lack of gas export is an unwritten political policy and originates mostly from the loss of its pricing formula and specialized analyzing of the pricing principles across the world and use of regional standards can solve this retardation
\end{abstract}

Keywords: natural gas, export, economic advantages, gas export contracts, energy, natural gas pricing

\section{Introduction}

Natural gas for reasons such as increasing environmental pollutants and global warming is highly significant because natural gas as a clean fuel in contrast with liquid fuels such as crude oil and other fuels such as coal given the changes happening in its market and the necessity of preserving the health of environment has been considered nowadays. Natural gas markets have tools to develop themselves, one of them is the export contracts, these contracts in traditional format are long term and are planned for 20-25 years periods that over the time and because of the economic requirements and various distribution of resources and the needs of the market some changes have been created. The main point in these changes is the contract pricing issue which is the principal issue in arranging the mutual relations both in long-term and short-term contracts. The significance of studying this issue in Iran has various reasons. First, Iran given the discovered natural gas resources and having the number one ranking in the world has no share in the world gas export and natural gas market. Second Iran has 7 neighbors in land boarders including Azerbaijan, Armenia, Afghanistan, Turkey, Iraq, and 8 neighbors in sea boarders including Kuwait, Saudi Arabia, Bahrain, Qatar, Emirates, Oman, Russia and Kazakhstan that almost all of them need natural gas. The gas export issue has been unsuccessful so far in the country and the main reason behind that is the lack of will or the ability of pricing the obtained gas regardless of issues such as the novelty of the gas industry, insistence of the internal advocates, and extraordinary internal use a flexible pricing formula in the face of market changes can be the way out of this dilemma. In this research it has been attempted to find an optimal solution to improve successful gas export to reach the aforementioned goals via a specialized analysis of the pricing issue of gas export contracts on the basis of the daily issues because despite the fact that Iran has large resources of natural gas and the student of this filed have largely explained these issues and transfer it but the author in this study has tried to transfer the concepts in a concise way to the reader and hopes to be efficient.

\section{Natural Gas}

\subsection{Natural Gas Definition}

Natural gas is a complex combination of carbohydrates with a little amount of non-organic combinations and one of the oil derivatives. Geologists and chemists believe that oil and gas are made of the remains of the animals and plants at the sea/lake depth along with the sediments that are created by sediment rocks. Processes through 
which the organic materials resources are converted into oil are not known and it is supposed that bacterial reactions at the depths under the pressure, pressure distribution, heat and natural distillation are among the influential factors and in addition to that the presence of hydrogen in deep resources, catalysts and the length of time are also influential. ${ }^{1}$

Natural gas usually exists with oil in oil reserves or separately in gas reserves. A significant part of the gas consists of methane. Methane is the simplest hydrocarbon molecule but along this simple matter there are some other combinations and the more the number of carbon atoms the heavier these combinations get. According to the standard codified in Iran's national gas company ${ }^{2}$ gas is a combination of light hydrocarbon that should have at least $80 \%$ of methane in itself. ${ }^{3}$

Natural gas market is a regional market and not a world market and it is formed in every region on the basis of the regional conditions. Therefore, there is a basic difference between the natural gas market and the crude oil and its products. The issue of transportation, liquidation and again gasification are among the main challenges ahead of the natural gas export that require lots of investment at all levels and stages. Differences in terms of political views and transit problems such as the political struggles between India and Pakistan which has exceeded the peace pipe line life to three decades are among the issues affecting the natural gas pricing issue. ${ }^{4}$

Technical features of gas include the degree of sweetness and sourness, richness in liquids such as gas condensatesand also Ethan $\mathrm{C} 3$ and $\mathrm{C} 4$, liquid gas more importantly the gas delivery conditions that can be sweet, sour or rich from the well, at refinery output and the delivery of gas as sweet and dry, in the destination by the pipe line, delivery at destination or source ${ }^{5}$ in LNG form is another challenge that at every stage requires lots of investment and directly affect the pricing formula.

The process of contract models and pricing are moving from long-term traditional methods towards modern methods especially in terms of the export of LNG and single-shipment and this issue should be considered in our country as well. And the slow progress of main and large markets of the region has led to insufficient speed of world scale model of natural gas sale and still the traditional models or a combination of them with the modern ones are implemented by the exporters. Given the capacities of Iran quick decision making is required to optimally put them in practice before these chances of development are not changed into threats or not lost in an optimistic vantage point.

\subsection{History of the Gas Industry of Iran}

The gas history may be divided into four parts, first stage which started with the first successful exploration of the oil field of MasjedSoleyman (burning stage) which was accompanied with burning the mixed gas along with producing oil. The most important event of this era which continued up to 1960s decade was allotting operation license or the privilege in 1916 for exploration and extraction of oil and gas for 70 years to a Georgian citizen named Khushtaria for Mazandaran, Gilan and Astarabad provinces and this operation license was never approved by the time parliament.

At second stage, which started from early 1960s in line with all level development of the country the gas production issue became a strategic issue so that Mohammad Reza Pahlavi in a lecture stated that "the flames which burn the wealth of people should quickly be extinguished" and following these words the king arranged the establishment of National Iranian Gas Company (NIGC) ${ }^{6}$ IN 1965, and after that the use of gas as the fuel for power plants was encouraged and supported and in 1964 natural gas for the first time was used as the material for Shiraz chemical fertilizer. After a couple of years for the first time in a non-trade purpose gas was used in Shiraz Namazi hospital by the gas pipe and it can be claimed that the serious development of gas industry happened in that 1960s decade and following the third and fourth administration of development programs of the country. One of the significant events of this period was the construction of country wide pipe line number one, Iran-USSR negotiations to transfer $5 / 6$ billion square meter gas annually in addition to transferring to the local market and also trying to export gas to European markets by negotiating with them at this time ${ }^{7}$.

\footnotetext{
${ }^{1}$ Roberts peter, Gas Sale Gas Transportation Agreement: principles and practice, London, Sweet .axwell,2004,p.116

${ }^{2}$ Standard M-CH-033 Iran's natural gas pipe lines qualitative features

${ }^{3}$ Dr. SaeedPakdesardasht oil gas industry in non-technical language an introduction to Iran's gas industry, Komeil publications-Tehran

${ }^{4}$ Ghanbarzade,M,2007, Unknown time of peace marathon, oil industry equipment journal, No.40 $5^{\text {th }}$ year, pp.22-25

${ }^{5} \mathrm{CIF}$ (Cost, Insurance \& freight) /FOB( Free On Board)

${ }^{6}$ National Iranian Gas Company (NIGC)

${ }^{7}$ E, Hassanzadeh. "Iran's natural gas industry in the post-revolutionary period". University of OXFORD. 2014
} 
The third stage started from the middle of 1970s decade and after the exploration of independent gas field of Shiraz and the gas industry entered into a new era besides increasing the gas production capacity Iran also did some negotiations with USSR to swap gas in order to export gas to West Germany and Europe and also the talks for exporting LNG of Kangan to Japan and America started and their contracts were annulled by the revolution council. In this period the first LNG project of the country under a contract with a Japanese-Norwegian and American consortium for the production of 4/8-7/2 square meter ton LNG annually from North Pars filed was signed. 70s decade was the blossoming period of Iran's gas industry that could make Iran the first role in exporting gas to the international markets.

After Islamic revolution gas industry because of the changes entered a new era all gas export contracts were annulled by the revolution council event the gas export to the USSR after that two countries could not come to an agreement on the conditions for extending and pricing it was cancelled in 1980. Although in 90s decade a number of actions were carried out in terms of gas export and studies were conducted to export 24 billion square meter daily LNG from South Pars to Japan which proved that the price of $\$ 5.30$ for every billion BTU was economically reasonable ${ }^{8}$.

In the years 1997-2005 some attempts were made in terms of export which also improved the internal market as well. In the third development program after the Islamic revolution the gas export became the second priority of the state after providing the local needs.

\subsection{Characteristics of Iranian Gas Industry}

As mentioned earlier our country Iran with $18 / 2$ percent of the explored resources has only 5percent of the world production and at the present time $4 / 8$ percent of it is used for local consumption. This lack of proportionality gets more significant when we know that first: the share of the common fields of the country is more than half of the all the gas resources and only 45 percent of it is in Southern Pars and the rest of it in common regions such as Salman, Arash, Foruzan etc. Second: Despite the fact that the local coverage of fuel for the consumption of various parts of industry, agriculture and domestic uses by the gas has considerably developed but we are far behind in terms of gas injection to reserves and the gas export. To answer the question in terms of the discrepancy between storage, production and the reason behind the current situation for the oil and gas industry we would explore the issue in detail.

The energy sector of the country and its dual role in terms of provision of energy and currency income for the country is the basic foundation of development and has always played a significant role in the development of the country ${ }^{9}$ and given the change of world willingness in increasing the consumption of gas as a chap energy commensurate with environment can influence the development of the country from various views and gas is also the raw material in the world chemical industry. Petrochemical products in addition to being exportable are used as the raw materials at lower hand industrial sectors and they have the capacity of being used in hundreds of other industries. On the other hand gas as the fuel in large energy industries can lead to reduction of final price of the manufactured products and facilitates the development of the industries ${ }^{10}$.

\section{Contracts of Selling Natural Gas}

Gas sale contracts are either long-term or short-term. In this part two types of these contracts are analyzed:

\subsection{Long-Term Contracts}

\subsubsection{Conditions of Delivery or Payment}

"Delivery or payment" condition is one of the non-price conditions of the contract and refers to this concept that the customer needs to pay for the price even he cannot extract the amount in contract. Delivery or payment is usually implemented at long-term contracts (15-25 years) to fulfill the primary investment obsolescence goal. Along with this condition some other conditions are mentioned through the contract to make it more flexible in terms of delivery or payment such as the percentage ${ }^{11}$ of delivery or payment or the condition to extend the basic period time ${ }^{2}$. For customers lower percentage of delivery or payment and longer period of delivery or payment is much more attractive ${ }^{3}$.

\footnotetext{
${ }^{8} \mathrm{E}$, Hassanzadeh. "Iran's natural gas industry in the post-revolutionary period". University of OXFORD. 2014

${ }^{9}$ Fetres; M/Teimuri B, 2012, access to economic development by the purpose of analyzing the weakness and strength of Iran Gas Industry, Oil and energy journal, special magazine of fourth energy convertors p31-49

${ }^{10}$ ibid

${ }^{11}$ Shiravi, A. and Ebrahimi, S. N., Exploration and Development of Iran's Oilfield Through Buy-back, Natural Resources Forum 30, Blackwell
} 
The least rate of delivery or payment of LNG and gas contracts has been reported at 70percent (Kiani ${ }^{3}, 1991$ ) and the period of delivery or payment is usually one year. This condition in 1950s entered the gas contracts as a standard condition. The basic economic rationale behind the use of delivery or payment of ensures the seller of the long-term income current for the massive primary investment obsolescence of the project and guarantees the financial provision of the project. Delivery or payment on the one hand makes the customers such as co-operation companies responsible for constant delivery to the consumers and on the other hand it is in relation with the policy of stable energy delivery. Therefore, delivery or payment reduces the impact of competition between fuels and gas distributors.

\subsubsection{Pricing Mechanism}

Pricing mechanism is not based on total costs therefore, benefiting from the construction cost reduction advantage and benefiting from liquidizing plant to a large extent depend on the power of buyers to use it as a tool to reduce the price. $^{12}$

In front of this view is the view of those who believe that opening the gas market which is now on the gone have led to the rise of risk at long-term investments on gas industry infrastructure and consequently rises the prices by the rise of costs. From such vantage point long-term contracts reduces the power imposition by the fluctuation of demand which would be to the benefit of the consumers.

\subsubsection{Destination Condition}

This condition is one of the conditions which highly affect the competitiveness of gas industry since on the basis of this condition producers under the power implementation of customers market which are mainly the large oil companies limit the distribution of gas in the signed contract it can be showed that the destination condition in case the transport cost and the demand rate is different at two places it might lead to a discriminating mechanism establishment which would increase the earnings of the producers. This condition no only through the price but also the reduction of liquidity of gas market influences the competition and leads to the behind the scene conspiracy of the producers.

\subsection{Short-Term Contracts}

In traditional long-term contracts the seller needs to deliver a certain amount of gas at a particular point determined in the contract in such contracts there is a chance that the gas price be dependent on the crude oil price or the products over a certain period of time and in this situation the risk of the price is upon the seller or that the buyer without considering opportunities that occur in other markets buy the gas at a defined price and in this case the risk of the price is upon the buyer. These contacts allowed a revision of the base price and the pricing formula indexes every three year times. Settlement of the problems and disagreements were carried out by the international judgment and the economic model was based on Asian crude oil or the European oil products, gas production and export is usually done by the exporters and for several decades it was a reasonable and popular structure. Traditional sale contracts were under pressure in most countries which was discussed in previous part ${ }^{13}$.

Free market affects the market structure in two ways first by changing the risk spread model which impact all of the oil chain and liquid gas and second by reducing the length of the long-term gas contracts which would lead to change of contracts combination.

In March of 2002 Malaysia 1 project, a 20 year contract was cancelled. From 1983 this project has annually exported to TEPCo and Tokyo gas respectively 4/8 and 2/6 million ton LNG. New negotiations lead to two levels first, a 4 year short-term contract by 7000000 tons to TEPCo and 500000 tons to Tokyo gas. The long-term of the contract was reduced to 15 years. In fact a short-term contract with more flexibility was inserted into long-term contract which was intended to increase the flexibility of the contract to a large extent. That is influential reduction at delivery and payment. Some unofficial reports reveal that the price has reduced at $5 \%$. Therefore, both the risk and price risk have been distributed. ${ }^{14}$

From the customers' vantage point the significance of the negotiations lie in the fall of risk because this contract enabled the buyer to in addition to accepting part of the risk take the responsibility of offering transport services chain which used to be done by the producer and take benefit of it. In other words, the significance of the $<$ new model of risk distribution> was the renewal profit distribution between buyers and sellers.

\footnotetext{
${ }^{12}$ Wright, J. \&Byrknes, A-H., "Buy-back Contract Risk Modeling Using System Dynamics”, Sustainability in the Third Millennium, 2000

${ }^{13}$ Roberts peter,Gas Sale Gas Transportation Agreement: principles and practice,London,Sweet . Maxwell,2004,p.116

${ }^{14}$ Wright, J. \&Byrknes, A-H., "Buy-back Contract Risk Modeling Using System Dynamics”, Sustainability in the Third Millennium, 2000
} 
The positive interpretation of this strategy is that buyers instead of accepting the cooperation risk in all of the LNG chain they get the new opportunity of profit division and optimize the LNG process. Experimental evidences in England and the United States of America show that there is a reverse relationship between freepricing and contract period. In both countries the share of long-term contracts in gas markets after free pricing has been significant. So that now only $50 \%$ and in England $85 \%$ of the contracts are long-term. In both countries the index of oil price partially or totally has been supplanted with single-cargo pricing.

\section{Features of Gas Sale Contracts}

\subsection{Determination of Gas; Mediating Conditions and Regulations}

According to the article 342 of the civil law ${ }^{15}$ which states that $<$ the amount and quality of the sales needs to be determined and its determination is based on weight, bushel, number, rug, or square or observation according to the local custom>. When the deal case is general to determine it needs to be determined from three aspects: identity, amount, and main features, by identity it means the nature and quality from which the deal case is formed and in the contract under the question natural gas or Hydrocarbon resources which include methane, ethane, propane, and hydrocarbon combinations are heavier such as Bhutan, pentane, hexane, heptane, and octane. The main features of the deal case refer to features that are significant in attracting the customer while they don't have any effect on the value of the deal case in other words, what is important in gas sale contract is the gas quality and in case of the loss of it would be considered as bereft of quality. Being determined or not the amount of gas that the customer over the contract period depends on the delivery which depends on gas sale from what type of the gas contract in the gas industry. Generally there are two types of contract in gas industry: Based on the nomination one is the preparation and delivery of gas and the other is the contract of assigning the gas field to the buyer.

\subsubsection{The Amount at Contract of Gas Preparation and Delivery}

In type one contracts that is gas preparation and delivery an article is homogeneous and the seller is responsible to deliver certain amount of it over a period to the customer the features of this type of contracts are:

-Lack of assigning a certain gas field: This contract in fact is the preparation and delivery of a certain amount of gas at a certain period of time where no gas field is assigned to the customer as the delivery source and the seller is free to deliver the gas to the customer from any gas filed he wishes. Therefore, it is possible that several customers receive gas from one gas field or a collection of fields under a separate contract.

\subsubsection{The Amount at the Contract Assigning a Gas Field to the Customer}

But in accord with the second type of contracts, the seller assigns a certain gas field to the customer and becomes engaged to all or part of a certain amount of gas which is economically advantageous produce for the customer. The following items are among these issues:

-assigning a single source for delivery to the customer: This case is the most significant feature of this contract and in fact gas is prepared from a certain source for the customer and delivered to the customer that usually and not always is under the monopoly of the special buyer.

-amount of the gas depends on the capacity of the gas field: Gas production at the beginning starts from small amount and at a time it reaches the stable point and after this period there would be a period of wane. Therefore, the amount of the gas on the basis of the contract depends on rise, stability and fall of the gas extraction of the gas field.

Contract cancellation: Although most of the contracts of assigning gas field have definite conditions and stable ones but they may have conditions for the benefit of the seller via which they cancel the gas production of that gas field because it is not economical

-Suitable for small and medium gas field: gas field assignment contract on one hand shows a number of features and these features are detected at small and medium gas fields and on the other hand in this type of contract the customer is merely a person and assigning a large gas field for a customer is not apposite.

Amid several sale classifications it can be stated that gas field assignment is closer to the general sale type because the seller is responsible to deliver a determined amount of gas o the customer over a certain period of time agreed within the contract. To exemplify the case consider the sale of 100 tons of wheat from a 1000 ton granary. Therefore, to observe the sale rules this contract is under article 351 of the civil law and the amount,

\footnotetext{
${ }^{15}$ Article 342 of the civil law: (the amount and the description of the article should be determined and its value is done via kilo, number or tillage or square meter in accord with the custom of the region)
} 
quality and features of the sale needs to be determined. As can be observed in the late case of gas sale contracts the amount of gas may be arranged on the basis of rise and fall of the gas storage and the amount of the contract can be under the influence of predictions of the gas storage capacity.

To recap, what is common in gas industry of Iran is signing the first type of contract types and on the basis of analyzed regulations according to the civil law it can be stated that these types of contracts are accurate but in terms of the second type of the contracts which are not in practice in Iran at the present time it seems that assigning the gas field to the customer does not mean giving the ownership and control privilege to the buyer and in this respect it does not contradict with the law concerning the state sovereignty on underground resources because as it was stated assigning single resources to distribute gas to the buyer merely means that gas from special resources for preparation and delivery to the customer become determined.

\subsection{Determining the Amount of Gas and Related Conditions}

In gas sale contracts generally customer is responsible to pay for the agreed price in the contract for the received gas and even in case willingly does not receive the gas and this amount of gas is less than the annual amount received over a year should pay the price of the total amount agreed in the contract. Such a regulation is called annual take or pay quantity ${ }^{16}$. In other words the customer need receive the gas amount which has been arranged in annual nomination ${ }^{17}$ and it should not be less than the minimum and maximum rate of the gas and pay for the contract price and in case of not receiving the gas pay a fine equal to the price ${ }^{18}$. In fact the rationale behind such a fine is to return primary investments, operation costs and coverage of the expected profit of the project (as will be discussed in the following part). The annual take or pay amount of gas is usually a percentage of 60-100 percent of the annual gas amount. Annual gas ${ }^{19}$ amount is not fixed and can be adjusted. ${ }^{20}$

\subsection{Gas Price Determination; Regulations and Adjustments}

Gas sale contract requires a condition upon which the price of the amount of gas which is delivered by the seller to the buyer is determined. Gas price depends on the fact that what is the unit of gas amount in the contract it can be on the basis of calorific value ${ }^{21}$ and it can be on the basis of volume ${ }^{2}$.

Also measured by square meter. For example, one square meter equals approximately $35 / 3$ square foot ${ }^{22}$.

\subsection{Gas Price Determination and Index Determination}

The purpose of pricing mechanism is to fulfill the long-term benefits of the seller and the buyer a price be agreed that the risks about the price equally be divided between two parts. For the seller as it was stated two purposes are considerable one is the price determination on the basis of gas value according to the market fluctuations and the contract period and the other is the provision of certainty for the producer in terms of the fundamental investment in gas fields. In the eyes of the buyer gas price change compared to the price of other fuels should compete with them in the market. Generally the purpose of the buyer of establishing the pricing mechanism is that the price of gas be so that it provide acceptable benefits for the buyer over the contract period. ${ }^{23}$

\subsubsection{Gas Price Determination}

Gas price can be determined on the basis of the locally announced prices in the local markets. For example in a contract where one part of the contract is England the BP gas price announcements can be used as the criterion to determine the gas price in the mutual contract. Therefore, in fact such a price either generally or partially shows a price that on the basis of the market changes over time. In long-term gas sale contracts sides of the contract have no interests in such contract since the gas price is likely to experience unexpected and sudden changes.

\footnotetext{
${ }^{16}$ annual take or pay quantity

${ }^{17}$ daily nomination

${ }^{18}$ Davey Henry,ááTake or pay"''andááSend or pay"'::A Legal Review and Long-Term Prognosis, Oil and . Gas Law and Taxation Review,Vol.15,Sweet Maxwell,1997,p.419

${ }^{19}$ annual contract quantity

${ }^{20}$ adjusted ACQ

${ }^{21}$ Thermal or calorific value refers to the amount of heat which is required to increase the temperature of a pound of pure water (453/59 $\left.\mathrm{g}\right)$ from 59 degrees Fahrenheit to 60 degrees Fahrenheit under absolute pressure of 14/7 is required. Its unit is BTU (British thermal unit) and it is measured by joule. BTU is equal to approximately 1055 joule.

${ }^{22}$ Volume refers to an amount of gas that under stable condition pressure of (14/7) and temperature (60 degrees Fahrenheit) it occupies a foot square. Gas volume is also measured by square meter. For example, one square meter equals approximately $35 / 3$ square foot.

${ }^{23}$ Coop Graham Laurent Gouiffes,Arbitration and Pricing Mechanisms in International Gas sale contracts, Oil,Gas Energy Low Intelligence,VolumeI,issue?02,www.gasandoil.com/ogel/,March 2003,p.3
} 
The other method is that the sides agree on a fixed price but the sides do not show any interest in this type of method as well because of the market changes over time the fixed price cannot reflect the relative value of the gas. Such a mechanism is usually implemented in short and middle term contracts. A method that can be used in long term methods and interested by the sides is an eclectic method.

In this method the sides first determine the trade situation and condition in a definite contract that the basic price over the time becomes adjusted on the basis of the defined criterion. ${ }^{24}$

\subsubsection{Determining the Index}

As we observed the ultimate purpose of determining the gas price is to record formula which can equally satisfy the requirements of the sides over the long term contract in the midst of the present changes in the market.

There is no priority among the aforementioned formula in terms of usage but a combination of them by the choice of any criterion by the sides so that they easily agree upon can be inserted into the contract.

The following indexes are indexes considered by the sides at the tie of selection: ${ }^{25}$

1) Crude oil price: change of crude oil price as the index for a customer which is the oil company it has a special acceptability because such a seller is familiar with the oil trade market and oil fluctuations. Instead does not have any interest in such an index because it is impossible that all earnings from the sale of load or gas consumption develop in a similar condition.

2) Price of oil products in international dealings: the seller that is an oil company for the aforementioned reasons has interest in oil products international price, such as gasoline (gas oil) and oven oil (black oil) with high sulfur or low as the index in the gas price.

3) Price of the oil products in local markets: buyer is more interested in oil products price in local market as the gas price criterion by this condition that the price of these byproducts to be the criterion in a market where the buyer intends to sell the products in it.

4) Price of electricity: Electricity price in the final consumer market is an optimal gas pricing criterion for the buyer in terms of its closeness to the gas price in a similar market.

5) Price of coal: For the buyer coal lacks the attraction because this fuel compared to gas is an impure fuel and has less energy rate and the rise of its price because of these features is very low. But when the buyer makes use of gas as the fuel for the production of electricity this product is optimal. For the same reason in special markets coal is considered as the fuel to produce power after gas.

6) Gas price: Competitive and fixed price of gas can be the best guide to determine the gas price. Because it shows at what rate the gas under the contract is competing. But this price cannot be used as the criterion in the contract because the use of competitive price of the gas in sale contracts can lead to continuity.

7) Inflation: The sides of the contract can insert the general inflation which is a reflection of the economic stability into the pricing formula.

In practice since it is a difficult task to find a criterion with the least fluctuation over the time in gas pricing formula a number of indexes and values equal or different are implemented. Therefore, determining any index and its value to be recorded in gas price formula is the result of negotiations between the side negotiations that are under the influence of a factor entitled base price. The higher the price the buyer would be stricter in indexes and the rate of its influence and vice versa.

\subsection{Gas Price Moderation and the Related Conditions to Revise the Price}

International contracts include conditions which allow the sides of the contract so that in case of the occurrence of certain events new negotiations to reach a new agreement and in case of lack of agreement choose the expert or the judiciary court so that the expert or the judge moderate, adjust or correct the conditions under the new economic conditions and the economic balance between the sides which they have considered at the time of agreement. Such conditions are generally referred to as the conditions about holding anew negotiations and correction and moderation. Although the theorists of contract issue have suggested the adage of such conditions but legal persons at international level usually at the time of signing the contract do not show any interest in adding it.

This lack of interest is because of the fear that these conditions can make the condition of the sides unpredictable,

\footnotetext{
${ }^{24}$ Trimble Niall,Understansing Gas Pricing Provision,Oil and Gas Law and Taxation Review,Vol.11, . Sweet Maxwell,1993,p.319

${ }^{25}$ Roberts Peter,op.cit.,pp.119.120
} 
increase the costs of the contracts and make the contract administration impossible, particularly since the expert or the judge makes a decision at the time of correcting or moderating that cannot be administered. ${ }^{26}$

\section{Formula Considered or Presented in Iran So Far}

Producer countries by the purpose of supporting the local industries have designed formula for pricing the gas delivered to them. In these formula first with a look at principle formative parameters of the final price it has been attempted to calculate such as: fixed investment costs, non-investment costs such as customs, insurance, etc. investment provision costs, operational, maintenance and repair costs, personnel, education, etc. and then for applying internal gas value parameters such as "ownership value" is defined and added to calculate the final cost and value of the gas and finally, it's the legislative power of the states which determines the amount of subsidy or discount on the price for various economic sectors. Although this pricing model is merely considered for the local market but it would certainly leave its effects on pricing formula of the export gas.

\subsection{Formula by the Programming Deputy of Oil Ministry}

Export prices of the programming deputy of the oil ministry has presented a report in 2006 in this respect and other issues related to the gas price and also products such as ethane by the use of the aforementioned frameworks. these formula are respectively as follows:

\subsubsection{First Model}

\section{A: On the basis of LNG}

The suggested price is defined on the basis of the added value:

Added economic value of each cubic meter

Where $\mathrm{p}$ stands for the price of $\mathrm{LNG}$ and $\mathrm{p}_{0}$ is the base price

But determining and measuring the added value of gas can always be the point of controversy between the sides and does not clarify the formula.

B: Gas pricing: Gas pricing has been suggested via three methods:

B-1 the price of the rival products in the destination country

$$
\mathrm{Pt}=\mathrm{Pt}-1+\sum_{i=1}^{t} \alpha \mathrm{i}(\mathrm{Bit}-\mathrm{Bi}(\mathrm{t}-1))
$$

B-2 the prevailing market price

$\mathrm{P}=\mathrm{PM}$

B-3 the price of the rival country's products in the destination country

$$
\mathrm{Pt}=\mathrm{Pt}-1+\mathrm{a}(\mathrm{Gt}-\mathrm{Gt}-1)+\mathrm{b}(\mathrm{Ft}-\mathrm{Ft}-1)
$$

Wherein:

$$
\begin{gathered}
\text { G- gasoline price } \\
\text { F-fuel oil }
\end{gathered}
$$

$$
\begin{array}{rc}
=\text { Pt annual pricetandand pt-1 } & - \\
\text { annual price Pt-1 } & - \\
\text { Brival products price } & - \\
\text { PM gas price in Europe } & \text { - }
\end{array}
$$

\subsubsection{Second Model}

The other model is to base the pricing on North Sea Brent Oil under the following formula:

$$
\mathrm{P}_{\mathrm{PGG}}=0.00179 \mathrm{P}_{\mathrm{br}}+0.675
$$

Where the Ppgg= gas price in Persian Gulf region

\section{$\mathrm{Pbr}=$ North Sea Brent Oil}

In the above models by a simple calculation it becomes clear that there is no significant difference with market prices. For example on the basis of the above formula the Persian Gulf gas price for $100 \$$ Brent oil equals $6 / 25$ $\$$ for every million BTU while by calculating with reverse price ${ }^{27}$ we get the numerical range of 6-7 dollar and in terms of the Japan's LNG which is around $11 \$$ in 2011 we get $7 / 5$ and for the year 2010 approximately

\footnotetext{
${ }^{26}$ Klaus Peter Berger,Renegatiation and Adaptiton of International Investment Contracts:the Role of . Contract Drafters and Arbitrators,Vand.J.,TransationalLaw,2003,pp.1348-1350

${ }^{27} \mathrm{Net}-\mathrm{Back}$
} 
$10 \$$ we get $6 / 5$ which shows that the result of the above mentioned formula is a bit higher compared to markets such as America where the price is around $4 \$$ but in comparison with the European markets which is around $8 \$$ and by subtracting the reconversion costs ${ }^{28}$ reaches to a figure between 6-7\$.

May be the weakness of this formula is that it always acts in a linear format and co coefficient which implement the influential events of the regional markets over the time in the formula has been observed. This problem also exists in the approved formula of the oil ministry which is merely connected to the Japanese oil basket and acts linearly. The fact that prices in various markets have been under the influence of different factors such as supply and demand and the future horizon and also they are influenced by the paper dealings and stock exchange market to a large extent and need to be considered. For example, American market has experienced expansive changes over the recent years in delivery sector and expansive utility of the sand $\mathrm{gas}^{29}$ has two messages. First, rise of the supply and second, hopeful horizon for the future in terms of the gas supply in that market because of the large size of the explored reserves of the above type and for the same reason we have witnesses a reduction of half the price in Europe.

\section{Pars-LNG formula to export LNG to Thailand}
$\mathbf{P}=0.035 \mathrm{JCC}+1.8$
for: $\mathrm{JCC}<20$
$\$ / b$.
$\mathbf{P}=0.075 \mathrm{JCC}+1$
for: $20<\mathrm{JCC}<40 \$ / \mathrm{b}$.
$\mathbf{P}=0.045 \mathrm{JCC}+2.2$
for: $\mathrm{JCC}>40$
$\$ / b$.

The above formula is in proportion with prices lower than $20 \$$ per barrel for the Japan's oil basket import ${ }^{30}$ with the market but is low for the higher prices

\section{Pars-LNG formula to export LNG to Thailand}

$\begin{array}{lll}\mathbf{P}=2 \$ / \mathrm{mm} \mathrm{BTU} & \text { for: } & \text { Brent }<26.67 \$ / \mathrm{b} . \\ \mathbf{P}=0.105 \times \text { Brent }-0.8 & \text { for: } & 26.67<\text { Brent }<60 \$ / \mathrm{b} . \\ \mathbf{P}=0.107 \times \text { Brent }-1.3 & \text { for: } & 60<\text { Brent }<71 \$ / \mathrm{b} . \\ \mathbf{P}=0.105 \times \text { Brent }-1.185 & \text { for: } & \text { Brent }>71 \$ / \mathrm{b} .\end{array}$

The obtained results are the same as that obtained from the export to Thailand

\subsection{Iran-LNG Formula}

$$
\mathrm{P}=0.065 \mathrm{Br}+1.2
$$

In general given the rise of the LNG prices in the years after the contract the prices seem low. For example in the North Sea Brent oil (80\$) the price of LNG on the basis of the above formula equals $7 / 7 / \$$ for every million BTU which is not in proportion with the current prices between 10-11 \$.

\section{Kuwait pipe line price:}

The only regional contract whose formula is based on the basis of regional oil baskets, natural gas export contract formula to Kuwait is as follows:

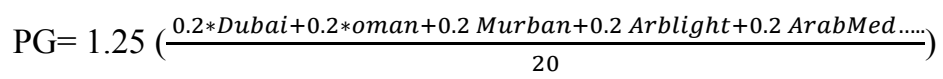

\footnotetext{
${ }^{28}$ Regasification

${ }^{29}$ Sand gas‘Shale Gas

${ }^{30} \mathrm{JCC}$
} 
Table 1. Natural Gas \& LNG prices formula for exporting from Iran

\begin{tabular}{|c|c|c|c|c|c|c|}
\hline $\begin{array}{ll}\text { Economic } & \text { evolution } \\
\text { workgroup } & \text { approved } \\
\text { formula } & \end{array}$ & $\begin{array}{l}\text { Persian } \\
\text { Gulf } \\
\text { natural gas } \\
\text { formula }\end{array}$ & $\begin{array}{l}\text { Export } \\
\text { Kuwait } \\
\text { formula }\end{array}$ & $\begin{array}{l}\text { Iran-LNG } \\
\text { formula }\end{array}$ & $\begin{array}{l}\text { Export to } \\
\text { Germany } \\
\text { formula }\end{array}$ & $\begin{array}{l}\text { Export to } \\
\text { Thailand } \\
\text { formula }\end{array}$ & $\begin{array}{l}\text { (minimum regional oil price) } \\
80 \$ p e r \text { barrel the gas price for } \\
\text { Kuwait equals } 5 \$ \text { for every } \\
\text { million BTU and with } 40 \$ \text { oil } 2 / 5 \\
\$ \text { for every million BTU would } \\
\text { reduce } \$ / m m B T U \\
\text { GAST TYPE }\end{array}$ \\
\hline \multirow{5}{*}{$\mathrm{P}=0.118 \mathrm{Jcc}-0.215$} & & $\begin{array}{ll}\mathrm{P}= & 0.2 \\
\text { (Dubai } & +\end{array}$ & \multirow{5}{*}{$\begin{array}{l}\mathrm{P}=0.065 \mathrm{Br}+ \\
1.2\end{array}$} & \multirow{5}{*}{$\begin{array}{l}\mathrm{P}=0.105 \\
\mathrm{Br}-1.185\end{array}$} & \multirow{5}{*}{$\begin{array}{l}\mathrm{P}=\quad 0.045 \\
\mathrm{JCC}+2.2\end{array}$} & \multirow{5}{*}{$\begin{array}{l}\text { Kuwait equals } 5 \$ \text { for every } \\
\text { million BTU and with } 40 \$ \text { oil } 2 / 5 \\
\$ \text { for every million BTU would } \\
\text { reduce } \$ / \mathrm{mmBTU} \\
\text { GAST TYPE }\end{array}$} \\
\hline & $\mathrm{P}=0.675+$ & Oman $\quad+$ & & & & \\
\hline & $0.179 \mathrm{Br}$ & Murb + A.L & & & & \\
\hline & & $+\mathrm{AM}) \quad \mathrm{x}$ & & & & \\
\hline & & $1.25 / 20$ & & & & \\
\hline $9 / 225$ & - & - & $6 / 4$ & $7 / 21$ & $5 / 8$ & $2010 \quad$ Liquidated natural gas \\
\hline $12 / 92$ & - & - & $8 / 16$ & $10 / 05$ & $7 / 2$ & (LNG) \\
\hline- & $5 / 35$ & 5 & - & - & - & \multirow{2}{*}{ Natural gas } \\
\hline- & $7 / 08$ & $6 / 54$ & - & - & - & \\
\hline \multicolumn{7}{|c|}{ Minimum prices at different markets } \\
\hline Japan & China & South Korea & $\begin{array}{l}\text { Middle } \\
\text { Europe }\end{array}$ & England & America & Countries \\
\hline $10 / 91$ & $6 / 09$ & $10 / 03$ & $9 / 51$ & - & - & \multirow{2}{*}{$\begin{array}{r}\text { Liquidated natural gas } \\
\text { (LNG) }\end{array}$} \\
\hline $16 / 64$ & $11 / 30$ & $14 / 94$ & $12 / 60$ & - & - & \\
\hline- & - & - & - & $6 / 56$ & $4 / 39$ & \multirow{2}{*}{ Natural gas } \\
\hline- & - & - & - & $9 / 80$ & $4 / 084$ & \\
\hline \multicolumn{7}{|c|}{ Net back gas price in different markets } \\
\hline & & & England & $\begin{array}{l}\text { South West of } \\
\text { Europe }\end{array}$ & $\begin{array}{l}\text { North East of } \\
\text { Asia }\end{array}$ & Year \\
\hline & & & & & & Liquidated natural gas \\
\hline & & & & & & (LNG) \\
\hline & & & & & & 2010 \\
\hline & & & $7 / 20$ & $8 / 26$ & $9 / 77$ & 2013 \\
\hline
\end{tabular}

The above formula is for Cent $/ \mathrm{m} 3$ that the result of the formula should be multiplied to $\mathrm{mmBTU} / \mathrm{\$}$. The calculation is shown at table 2

Table 2. Calculation method of table 1 formula

\begin{tabular}{ll}
\hline $\begin{array}{l}\text { Gas export formula to Thailand } \\
2013\end{array}$ & $\mathrm{P}=0.045+\mathrm{JCC}+2.2=0.045 * 111.29+2.2=7.2$ \\
\hline Iran formula LNG & $\mathrm{P}=0.065+\mathrm{Br}+1.2=0.065 * 107.02+1.2=8.16$ \\
\hline Export to Germany formula & $\mathrm{P}=0.105+\mathrm{Br}-1.185=0.105 * 107.02-1.185=10.05$ \\
\hline Persian Gas natural gas formula & $\mathrm{P}=0.675+0.179 \mathrm{Br} * 35.7 / 100=0.675+0.179 * 107.02 * 35.7 / 100=7.08$ \\
\hline $\begin{array}{l}\text { Economic work group approved } \\
\text { formula }\end{array}$ & $\mathrm{P}=0.118 \mathrm{JCC}-0.215=0.118 * 111.29-0.215=12.92$ \\
\hline Export to Kuwait formula & $\mathrm{P}=\frac{1.25[0.2(\mathrm{D}+0+\mathrm{M}+\mathrm{AL}+\mathrm{AM})]=1.25 *[0.2(103.90+103.90+106.08+105.78+103.93)]}{20}$ \\
\hline
\end{tabular}


Table 3. Minimum LNG price at different markets

\begin{tabular}{cc}
\hline Regional markets & Minimum LNG price (reverse price calculation) dollar every million BTU \\
\hline North East Asia & $9 / 77$ \\
South West Europe & $8 / 26$ \\
England & $7 / 20$ \\
\hline
\end{tabular}

Table 4. Single cargo markets price

\begin{tabular}{ll}
\hline Country & 2013 \\
\hline US (Henry Hub) & 4.084 \\
US (Nymax) & 4.255 \\
UK & 9.80 \\
China & 11.80 \\
South Korea & 14.94 \\
Japan & 16.64 \\
India & 14.10 \\
\hline
\end{tabular}

\section{Numerical analysis of the formula}

Table 1 is an instance of obtained prices from the aforementioned formula by the assumption of $80 \$$ for every oil barrel and also the actual prices of the years 2010 and 2013 are presented and also show the actual prices of gas trade and LNG in different markets of Europe, Asia and America and also on the basis of the net-back calculation of prices $^{31}$ in main Asian (East Asia), Europe (South West) and also America are presented. This table shows that:

\section{Apposite Formula for Iran's Gas Pricing}

On the basis of the aforementioned issues and presented explanation in terms of the identity and the type of performance of the gas trade market and the significance of gas export for the country the following pricing models are presented in the following two methods:

Model 1: Pricing formula will be related to the liquidated gas or LNG (base price)

Model 2: Pricing formula will be related to the crude oil of the region as the base price

\subsection{First Model: By the Use of LNG Prices}

\subsubsection{The Reason to Choose Model 1}

As earlier stated LNG is the very natural gas which has been liquidated via a process and transferable and through another process it is converted into gas in the destination ${ }^{32}$. All stages of liquidation, transference, and re-gasification and the related costs can be assessed and that the price of LNG in large markets that is East Asia and Far East including Korea, China, India and also Europe are announced and accessible.

\subsubsection{Purpose of the Model}

In this model the same as Model 2 we intend to reach formula for gas pricing calculation in the region that encourages gas trade in the region. In these models it is attempted to calculate simplest formula for gas pricing as follows:

Sour gas price in the destination country

Sweet gas price in the destination PGD (neighboring country)

Sour gas price deliverable at the well
Sweet gas price deliverable by the coast by the pipe line (FOB)

Sweet gas price deliverable at sea boarder

PG

PGB

PAGW Sweet gas price at the well 


\subsubsection{Details of Formula Foundations}

The general foundations of formula were previously discussed and they are discussed in detail as follows:

-Although Qatar as the largest LNG exporter has more roles in pricing formula but to reduce any risk error other exporters of the region such as Oman and Emirates would have a less role in the formula.

-In determining prices the most LNG export of the region is first to Japan, Korea, Europe and finally China and India therefore in this formula for each of the above markets a role has been considered. Therefore, the following formula for determining middle LNG price in the region is suggested for every fiscal year.

$$
\operatorname{PLNG}(\text { cif })=0.3 \mathrm{QL}+0.2(\mathrm{OL}+\mathrm{EL})+0.3(\text { Ave. } \mathrm{Eu}+\text { In. Ch. })
$$

In.: the average price of annual import from India

Ch.: the average price of the annual import from China

El: the average price of the annual export from Emirates to Japan and Taiwan
$\mathrm{P}=\mathrm{LNG}$ (cif) the average price of $\mathrm{LNG}$ delivered to all above markets by the regional exporters "base price"

QL: the average price of the annual export of LNG by Qatar to Japan and Korea

OL: the average price of LNG export from Oman to Japan and Korea

EU: the average price of annual import from Europe

"Word Gas Intelligence" announces all the above mentioned prices therefore they can be implemented as the base price.

6.1.4 Calculation Method and Reaching Practical Formula of Model 1

As stated earlier natural gas covers the following stages from the source of the destination:

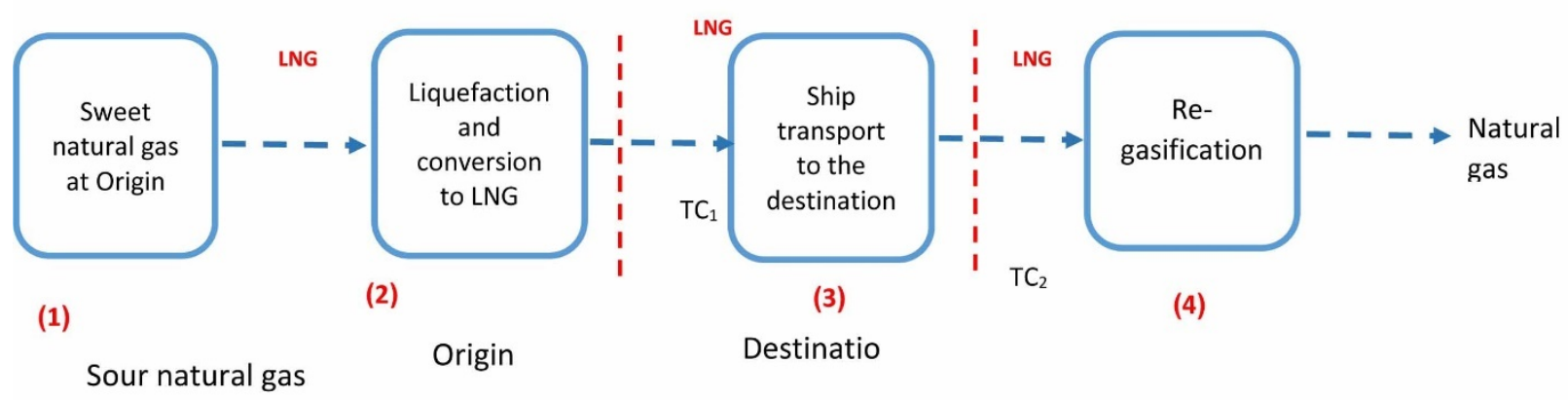

Figure 1. LNG transport diagram

The purpose of the intended formula is to determine the best price in the first stage that is "sweet gas price in the destination which is called $\mathrm{P}_{\mathrm{G}}$ " and showed that for this purpose the regional LNG prices are applied and on the basis of the above formula 1 and by calculating (P LNGCif) starts and calculate the costs of stages 3 and 2 from the diagram after subtracting from (P LNGCif) at the price of sweet natural gas at the source $\left(\mathrm{P}_{\mathrm{G}}\right)$. Therefore, first the LNG price at the source with LNG in the destination is calculated. According to the diagram the difference between them is the insurance and transport costs: To calculate the transport cost the following issues are considered:

-Given the fact that the destination of the majority of the regional LNG is markets of Japan, China, Korea, and India in Asia and also South and West of Europe such as Italy, Spain, Germany, France and that the average cost of transport to Asian markets and European market considering the fact that the passage of ships from the Cape of Good Hope or the Suez Canal does not make big difference then for our purpose and to simplify the calculation formula they are considered the same and a single transport cost is considered.

-To include the impact of future years changes on transport costs and at the same time simplifying them we consider the transport costs as the LNG costs as a percentage of the price.

-To find the above percentage the daily actual figures of the market were applied in a percentile format in the formula.

The cost of transport from the region to the aforementioned markets in the years of study were around $70-80$ 
dollars per ton and the LNG price in those markets were around 500 dollars per ton therefore the ratio between them would be around $15 \%$. In other words, the LNG cargo to reach the markets such as Japan or Europe around $15 \%$ of its price in Persian Gulf need to be expended and transport insurance is also added to this amount which is around $1 \%$ of the value of the cargo. Therefore, it would be $16 \%$ of the value of the cargo. Therefore,

$$
\begin{gathered}
\left(\mathrm{LNG}(\mathrm{CIF})-\left(\mathrm{T}_{\mathrm{c}}+\mathrm{I}_{\mathrm{C}}\right)=\mathrm{LNG}(\mathrm{FOB}=\mathrm{P} \text { LNG- }(15+1) \%\right. \\
\mathrm{P}_{\mathrm{LNG}(\mathrm{FOB})}=0.84 \mathrm{P}_{\mathrm{LNG}(\mathrm{Cif})}
\end{gathered}
$$

\subsection{Second Model: By the Use of Oil Prices}

As mentioned earlier different formula which are mainly related to the oil import basket of Japan ${ }^{33}$ and North Sea Brent have been presented in Iran oil industry for the export of gas as LNG whose features and discussions were put forward in previous parts.

The biggest problem of the aforementioned formula which separates them from the facts of the regional market is the relationship with the markets of Japan and Europe which have two different conditions compared with the region and that in these formula Persian Gulf oil which are announced by stock exchanges and credible institutes such as Petroleum Argus, Platts etc. except for the export to Kuwait.

The other problem is both the geographical and price differences and the distance of these markets with the region. Japan is the most expensive and buyer of LNG and Europe is also LNG buyer while the price difference at all economic parameters such as energy is different from the Persian Gulf. In this discussion and analysis of the formula it was revealed that Iran LNG formula $(\mathrm{P}=0.65$ Brent +1.2$)$ is actually closer to realities of the market and it seems to be a simple and at the same time more practical formula. Its dependence is totally on North Sea Brent oil which there is no proportionality for the continuation of this congruence over long

term because the Brent prices are dependent on the supply and demand conditions of gas and oil which is different from the Persian Gulf situation. Therefore, it seems that it is better to make use of the regional pricing base which is more proportionate with that of the conditions and at the same time it is suggested to make use of a basket of these oils for the sake of reducing the probable risks.

\section{Conclusion}

On the basis of all the data, facts and the analysis of the earlier parts there is a need of defining natural gas pricing formula which is today a significant hurdle against the development of the country in terms of export table 5show the rate of lagging behind in terms of gas export in proportion with other countries with lower reserves which were discussed earlier in detail.

\begin{tabular}{|c|c|c|c|c|c|}
\hline $\begin{array}{l}\text { Share of the world } \\
\text { gas market } \\
\text { (percent) }\end{array}$ & $\begin{array}{l}\text { Export share } \\
\text { compared to reserves } \\
\text { (percent) }\end{array}$ & $\begin{array}{l}\text { Rate of gas export in } \\
\text { 2013(billion cubic } \\
\text { meter) }\end{array}$ & $\begin{array}{l}\text { Oil reserve percentage } \\
\text { to world reserve } \\
\text { percentage }\end{array}$ & $\begin{array}{l}\text { Gas reserves } \\
\text { amount(trillion cubic } \\
\text { meter) }\end{array}$ & Country \\
\hline $7 / 6$ & $3 / 94$ & $78 / 9$ & $10 / 3$ & 2 & Canada \\
\hline $9 / 9$ & $5 / 11$ & $102 / 4$ & $0 / 5$ & 2 & Norway \\
\hline $12 / 1$ & $0 / 51$ & $125 / 5$ & $1 / 5$ & $24 / 7$ & Qatar \\
\hline $5 / 1$ & $5 / 9$ & $35 / 4$ & ---- & $0 / 9$ & Holland \\
\hline $1 / 3$ & $6 / 75$ & $13 / 5$ & $0 / 2$ & $0 / 2$ & England \\
\hline $4 / 1$ & $0 / 95$ & $42 / 9$ & $0 / 7$ & $4 / 5$ & Algeria \\
\hline 3 & $1 / 07$ & $31 / 3$ & $0 / 2$ & $2 / 9$ & Indonesia \\
\hline $2 / 9$ & $0 / 81$ & $30 / 2$ & $0 / 2$ & $3 / 7$ & Australia \\
\hline $3 / 2$ & $3 / 07$ & $33 / 8$ & $0 / 2$ & $1 / 1$ & Malaysia \\
\hline $0 / 9$ & $0 / 027$ & $9 / 4$ & $9 / 3$ & $33 / 8$ & Iran \\
\hline $185 / 7$ & \multicolumn{5}{|c|}{ All of the explores reserves of the world (trillion cubic meter) } \\
\hline $1035 / 9$ & \multicolumn{5}{|c|}{ All of the world exports in 2013} \\
\hline
\end{tabular}

Table 5. Our country's gas market share

${ }^{33} \mathrm{JCC}$ 
It can be concluded from studying this table that although Iran possess gas reserves 17 times more than Canada 17 times more than Norway17 times more than Holland17 times more than Algeria 17 times more than Indonesia17 times more than Australia17 times more than Malaysia the share of Iran's export compared to them is $12 \%$ of Canada, $9 \%$ of Norway, $7 \%$ of Qatar, $18 \%$ of Holland, 70 percent of England, $22 \%$ of Algeria, 30 percent of Indonesia, $28 \%$ of Malaysia, $31 \%$ of Australia which shows the big distance in between Iran and the aforementioned industrial and non-industrial countries in terms of gas export. On the basis of the analyses conducted in this thesis and the necessity of determining a natural gas pricing formula and the advantages of the necessity of export three conclusions can be obtained by changing Iran to the main gas exporter of the region.

\section{-Costs:}

It is absolute that the connection of country's gas network to the neighbor countries' that only by constructing pipelines and with the least cost compared to that of constructing LNG units with lots of investment and transporting it by special ships to other regions is much cheaper. But it needs to be considered that the consumption market likes to have a share of the reduction of costs of gas transport and be included in the pricing formula. The calculations conducted in earlier parts show the small role of transport in case of the use of pipeline for near distances compared to transport cost in LNG form.

Besides that heavy costs of investment both in source to change gas into liquid (LNG) and at destination for the terminals special for LNG reception and it conversion into natural gas makes export by pipeline more optimal than long-distance export.

This rational only include the fact that in terms of gas export to the world markets the priority is with the neighboring countries and via pipeline but it does not mean abandoning other large and far markets such as China, India, Korea, Japan and Singapore and the rest of the Europe which requires making necessary investments and timely investment in LNG industry, gas swap, and its marketing in the destination markets because the high potential of the gas production of the country in a coordinated and strategic program for gas trade does not allow the state gas industry and the world trade be limited only to the neighbors.

-Gas pricing because of it unequal distribution across the world, the impact of distance between source and destination on the transport costs and other reasons which were discussed in this thesis are in force regionally and not internationally while some attempts have been made to globalize it through single product markets but this industry is quite young compared to markets such as international oil market.

-Lack of natural gas pricing in middle East and in particular in our country Iran has always been confronted with political and non-specialized views so that in few attempts made several problems have been mentioned and has weakened the sufficient will for it and in other words has eliminated the required incentive for it in the development of this industry.

Given the large mass of reserves and the presence of 14 neighbors in need of gas long term flexible contracts in the face of market fluctuations can establish the development of natural gas market development in the region that we discuss its advantages in the following part.

-These apposite conditions in line with the world changes can also establish the foundations for the creation of a pricing center on a daily basis and a single product market, establishing expert centers regardless of the political tastes can make our country the number one gas seller in the region, geographical condition of the country, the rate of the reserves, and other foundations discussed in the present study has facilitated this big attempt to a large extent.

-To choose the best method of pricing which has been analyzed in this study on the basis of the current condition in the region depending on the crude oil of the region or its thermal value or the LNG price in other markets so that they have flexibility in the face of market changes can help the country out of the dilemma of pricing the gas.

-Iran by possessing the largest world gas reserves can first consider the gas export through pipeline to the neighboring countries and then be establishing regional co-operations to create regional or beyond-regional pipelines get access to East and West markets of Europe and if possible gas swap and administering gas liquidation to issue to far markets and become the main player of the world gas market because the afore mentioned capacities that young gas industry of the country not only after reaching these goals can also benefit from political advantages of this achievement and ensure economic-political relations with the world of consumption and secure the security and stability of the relations. 


\section{Suggestions}

1) It is suggested to continue this study in terms of the positive environmental impacts and improving the international relations of the country to follow the international human treaties this research is an emphasis on lack of environmental pollution

2) It is suggested for natural gas pricing from the regional reference pricing or LNG at destination markets

3) It is suggested that for completing the present study a comprehensive analysis be conducted in terms of decision making structure of the natural gas of the country to unite imposed policies in this sector.

\section{References}

Berger, K. P. (2003). Renegatiation and Adaptiton of International Investment Contracts: the Role of Contract Drafters and Arbitrators, Vand. J., Transational Law, pp.1969-1971.

Coop Graham Laurent Gouiffes. (2003). Arbitration and Pricing Mechanisms in International Gas sale contracts. Oil, Gas Energy Low Intelligence, I(2).

Fetres, Mohammad teimoori, B. (2007). access to economic development by the purpose of reinforcing weaknesses as well as strengths in gas industry of Iran, oil and gas industry fourth conference of energy convertor, p31-49.

Hassanzadeh, E. (2014). Iran's natural gas industry in the post-revolutionary period. University of Oxford.

Henry, D. (1997). "Take or pay" and "Send or pay": A Legal Review and Long-Term Prognosis. Oil and Gas Law and Taxation Review, 15, 419.

Maryam, G. (2007). peace marathon indefinite time. oil industry facilities journal, (40), 22-25.

Pakseresht, S. (2014). oil gas industry in non technical language, familiarity with the gas industry of Iran, Komeil publications, pp.48-63.

Roberts, P. (2004). Gas Sale Gas Transportation Agreement: principles and practice. London, Sweet. Axwell. p.116.

Shiravi, A., \& Ebrahimi, S. N. (n.d.). Exploration and Development of Iran's Oilfield Through Buy-back. Natural Resources Forum.

Trimble, N. (1993). Understansing Gas Pricing Provision. Oil and Gas Law and Taxation Review,Vol. 11, Sweet Maxwell, p.319.

Wright, J., \& Byrknes, A.-H. (2000). Buy-back Contract Risk Modeling Using System Dynamics. Sustainability in the Third Millennium.

\section{Copyrights}

Copyright for this article is retained by the author(s), with first publication rights granted to the journal.

This is an open-access article distributed under the terms and conditions of the Creative Commons Attribution license (http://creativecommons.org/licenses/by/3.0/). 